\title{
The Helix of Human Cognition: Knowledge Management According to DIKW, E2E, and the Proposed View
}

\author{
Zbigniew J. Gackowski \\ California State University Stanislaus, Turlock, CA, USA
}

\section{zgackowski@csustan.edu}

\begin{abstract}
This is a theoretical paper; it presents the author's position about how to improve on the commonly disparate thinking about information, data, knowledge, concepts, and wisdom by viewing them pragmatically through the lens of decision making as factors in operations. It refers to the traditional Data-Information-Knowledge-Wisdom (DIKW) Hierarchy, considered by some as the canon of information science and knowledge management and the Existence to Enlightenment (E2E) model. Both have been critically reviewed and their weaknesses exposed. Scholars' views attest to how divorced they may become from practice and academic postulates worthy of attention. Information, when viewed as a symbolic pattern of physical states that represents a factor for operations or for extension of replicable knowledge, offers a platform and framework for verifiable reasoning and testing of hypotheses with improved transparency, which is the main objective of this paper. It emphasizes the natural semantics of pragmatic consequences of informing in contrast to linguistic semantics emphasized by most academicians.
\end{abstract}

Keywords: Reality, existence, cognition, understanding, DIKW hierarchy, primary information, secondary information, facts, primary data, secondary data, materiality, quality assurance, natural semantics, linguistic semantics.

Motto: Attributing cognitive uncertainty and subjectivity of communicating entities to the communicated information is as delusional as attributing movements of the planet Earth to the Sun.

\section{Section 1: Introduction}

In some respects, our "age of information” resembles the pre-Copernicus era in astronomy. Cognitive problems of uncertainty and subjectivity that are experienced by communicating entities (informing entities and entities informed) are attributed to information they exchange. When information (a message or a communication) is viewed as anything "in form"-a pattern of physi-

Material published as part of this publication, either on-line or in print, is copyrighted by the Informing Science Institute. Permission to make digital or paper copy of part or all of these works for personal or classroom use is granted without fee provided that the copies are not made or distributed for profit or commercial advantage AND that copies 1 ) bear this notice in full and 2) give the full citation on the first page. It is permissible to abstract these works so long as credit is given. To copy in all other cases or to republish or to post on a server or to redistribute to lists requires specific permission and payment of a fee. Contact Publisher@InformingScience.org to request redistribution permission. cal states that plays a role only with regard to its form as a factor for operations (e.g., identifier, time, location in drone attacks) — it reminds us of blaming the messenger for the message, just as much of a delusion as attributing movements of our planet Earth to the Sun. Disparate views abound in scholarly literature. Frequently, a wide chasm separates views among academicians and the views of practitioners. This 
physical and pragmatic approach offers a platform and framework for verifiable reasoning of improved transparency and cohesion.

Frank Blackler (1995), in his seminal study, outlined an alternative approach to knowledge. He considers the term, knowing, to be more appropriate, because he views knowledge as a complex process that is mediated, situated, provisional, pragmatic, and contested. Martin Fricke (2009) reviewed the Data-Information-Knowledge-Wisdom (DIKW) Hierarchy as "part of the canon of information science and management." He identified a central logical error in DIKW, offered arguments that the hierarchy is unsound and methodologically undesirable, and offered some alternatives. About the same time, Jean-Baptiste P. L. Faucher, Andre M. Everett, and Rob Lawson (2008) embarked independently upon reconstituting knowledge management. These researchers move away from the hierarchical relationships among data, information, knowledge, and wisdom and offer a new model from Existence to Enlightenment (E2E) as a "cognitive system of knowledge" that redefines the scope of knowledge management. They criticize the current approaches, saying that they lack clear boundaries of knowledge, so they add Existence at the lower end and Enlightenment at the higher end. The latter two efforts partially complement each other, but both ignore most of Blackler's postulates regarding knowledge and the need for quality assurance and feedback in knowledge management, which is surprising in light of the nearly two-decade-long MIT Information Quality (MITIQ) Program (http://mitiq.mit.edu/MITIQ/MITIQ.aspx) that studies and promotes information quality.

This paper proposes a further departure from the current way of thinking. On the one hand, one may accept some elements of their critiques: (a) Fricke's (2009) critique of the DIKW Hierarchy, and (b) the implicit critique by Faucher et al. (2008) of the hierarchy and the extension of the model by Existence (see Section 2). On the other hand, a physical and pragmatic approach to information is proposed, where data are purely human constructs and are subsets of information. Knowledge management must deal with a broad scope of information, data, and other elements of knowledge from the rigorous to the esoteric.

This is a theoretical paper that presents the author's position in a positivist down-to-earth manner that views information and informing as natural physical phenomena that are interpreted pragmatically; it makes no references to ontology, about the nature of being, and to epistemology, which studies the nature of knowledge. Specifically, this approach:

1. views increments of understanding through the pragmatic lens of decision making to act

2. emphasizes the use of natural semantics of material pragmatic consequences

3. recognizes a gradual linear additive of the quantitative extension of understanding until a critical point is reached that triggers qualitative changes

4. postulates the universal teleological perspectivism and relativity of assessing increments of understanding with regard to defined purposes within defined contexts

5. limits (initially) its scope only to provable or replicable increments of knowledge

6. limits (initially) interpretation of information, data, elements of knowledge, and wisdom to anything in form as patterns of physical states that represent a factor in operation or extension of knowledge in contrast to patterns in substance that must be transported to be translated in space

7. distinguishes primary information from secondary information and primary data from secondary data that are obtained in the processes of, respectively, primary and secondary informing

8. explicitly requires quality assurance of every increment of understanding 
9. explicitly incorporates feedback and feedforward (control) flows of information to keep information, data, knowledge, and wisdom current in managed knowledge bases

10. complies with the fundamental tenets of the mathematical theory of communications (Shannon \& Weaver, 1949) and the qualitative theory of information (Mazur, 1979)

Section 2 of this paper criticizes the notion of existence as presented by Faucher et al. (2008) and contrasts it with this author's view. Section 3 enumerates the necessary conditions that make information operationally informative. Section 4 presents the rationale for distinguishing primary from secondary information with quality assurance of their factual nature that ultimately leads to factual, reliable data. Section 5 criticizes the prevailing presentation of data as divorced from best practices and deprived of defined perspective, operational context, and pragmatic materiality. Section 6 does the same with respect to information by considering it on equal terms with other operational factors, including those in substance that objectively impact results of actions. Section 7 discusses materiality as the fundamental, central, and the most pervasive use requirements that reigns supreme over other aspects of quality of factors in operations. Section 8 focuses on the role of secondary information and secondary data of ensured quality for storing and processing them by computers.

Sections 1 through 6 discuss the role of primary information and primary data, as distinguished from secondary information and secondary data (later combined with other components of knowledge and discussed in Section 9). Section 10 covers concepts, models, and pragmatically viewed enlightenment, while Section 11 briefly discusses real-life operations within which everything is ultimately tested: information, data, elements of knowledge, concepts, and even the pragmatic aspects of wisdom. Section 12 discusses wisdom as knowing how to use what we know with all its inherent pragmatic limitations. Section 13 discusses the controversy of intangibility, subjectivity, and materiality of factors in form. Section 14 presents the ascending and expanding helix of human cognition, while Section 15 summarizes all of the above. This paper is presented for challenge, critique, and discussion.

Besides informing taking place in peer-reviewed conference presentations, papers in peerreviewed journals, scholarly books, and textbooks, there is another undercurrent of informing that takes place between authors, reviewers, and editors and is invisible to the public eye. Reviewers, like others, also offer disparate views. The reader will be given a glimpse into this less-visible informing. The evidence actually exists but is blinded; hence, it cannot be presented the same way as other statements. The reader should be aware of it.

\section{Section 2: Existence: Reality as Presented in Experience}

Faucher et al. (2008) write, "Existence describes the whole environment that humans can grasp and create data about. It is a state of being that constitutes the lower end of the knowledge system" (p. 8). One may argue, however, that existence rather exists than describes anything. The Merriam-Webster definition of existence, "reality as presented in experience," serves better, and, contrary to the above claims, views it first as a process of experiencing reality.

Anyone who is prudent should beware of data that are created by humans instead of data that are faithfully derived from reality or existence and scrutinized by others. Knowledge or knowing is (and should be) contested according to Blackler (1995, p. 1042); however, it is not an issue of domination and subordination, as he suggests, but a necessary requirement for operational reliability of knowledge. With data there is no room for creativity except in designing a clever way of deriving them from reality. To stay on solid ground, whatever humans "can grasp" should be critically scrutinized by others whether it faithfully maps reality or contingencies. Thus, the quoted introductory statement requires caution. 
We all deal with reality that consists of objects, events, acting subjects, and their corresponding properties and relationships. They can be described by states that are intrinsic to entities and their states relative to other entities. Schopenhauer, in his opus vitae titled "The world as will and representation," made available to English readers by Hamlyn in 1980, views actions as interplays between will and representations. Available representations are the only reality for acting subjects. In today's parlance, representations are information, data, knowledge, concepts, wisdom, and maybe other not-yet-defined patterns in form; they are the virtual reality within which humans act. Representations of existence may facilitate or inhibit operations, which makes them factors, meant as anything that affects results. Factors should be analyzed within a specific operational context, where they are "situated" in contrast to "abstract and decontextualized knowledge” (Blackler, 1995, p. 1042).

Some factors are in substance (e.g., a knife) and some in form only (e.g., identification, location, and timing of a target); the latter are of a symbolic nature, of no other role on their own except their form, and commonly referred to as information in general. Actions may be caused by changes in representations, emotions, or results from reasoning by intellect or inference engines. Actors construct mental or formal models of situations that initially are static, based only on the available data - the givens-however, reality is in flux. To keep models current, reality must be monitored by observing and testing.

\section{Section 3: Information and Informativeness}

Thus, acquired information must be scrutinized to check whether it is factual (provable, or replicable), actionably reliable, and operationally informative; that is, how pragmatically it affects models; subsequent decisions; and, finally, the results. Information, as a factor in form, may be:

1. operationally irrelevant because it does not pertain to any component of a mental, physical, or formal model; then it is NOT operationally informative.

2. operationally relevant but overlaps what is already known; thus, it does not change the model, the entropy of the situation (a statistical measure of the disorder or randomness in a closed system), and is associated with a zero amount of information, as defined by Shannon and Weaver (1949); then it is NOT operationally informative;

3. operationally relevant, but of no pragmatic meaning, as it makes no difference in results (for instance, an additional amount of any factor above the indispensable does not impact or only marginally impacts the results); then it is NOT informative and of no effective use;

4. operationally relevant, of operational meaning, but it only quantitatively changes the results; then it is quantitatively operationally informative (not in science, but in operations; the quantitative changes must be significant); or

5. operationally relevant, of operational meaning, and it qualitatively changes the model, the way it is implemented, and/or the results of operations; then it is qualitatively operationally informative and requires a subsequent redefinition of the affected model.

Here the reader can find the first demonstration of how this study emphasizes the use of natural semantics of pragmatic material consequences of informing in contrast to the linguistic semantics preferred by many academicians. Immersed in linguistic semantics, academicians tend to ignore the natural one, as will be shown again in Section 4. In operations, linguistic semantics play a secondary role and frequently is overridden by the natural one. Even worse, it may be used to encrypt, distort, or hide the pragmatic meaning of operations. For instance, a code word, "operation peace,” may trigger a vicious pacification of a village with no survivors left. Terminology and titles of many legislative acts remind us of this widespread practice to contort and hide their pragmatic consequences; this is done to sell them more easily to the unaware public. A physical 
view of information, data, knowledge, and concepts as patterns of physical states that represent factors in operations provides a sound platform for verifiable reasoning and testing of hypotheses in contrast to the views within the DIKW Hierarchy, the E2E model, and those found in glossaries of MIS textbooks, which are broadly discussed by Gackowski (2012a).

\section{Section 4: Primary Informing, Primary Information, and Data}

Humans (e.g., researchers, observers, intelligence officers, managers) communicate by exchanging patterns in form. On the receiving end, those patterns meet sensors of living entities or robotic devices (supported or not by instruments). In common parlance, anything in form only is labeled information. The presented approach starts with the most basic interpretation of the term, information. For some it is too simplistic; for others it is the strongest and most potent. Stonier (1997) believes that "information is an intrinsic component of all physical systems ...." (p. 12) (the third essence that supplements matter and energy in viewing the universe) that describes structural aspects of systems. Within this view, information is a natural, intrinsic, always present, and objectively observable aspect of viewing physical systems ascribed to their organization or lack thereof. Thus, viewed information does not require observers and does not need to be observed or understood (e.g., genes, seeds), but it works amazingly in the universe.

Received patterns in form, images of the originals, generated by informing entities, constitute primary information acquired by primary informing within human cognitive experience. Usually, they are converted to other (supposedly equivalent) patterns more suitable for recording, processing, memorizing, or storing. Images represent originals at some degree of fidelity. Although no academic reviewer had questioned the proposed distinction, many advised reaching out to Bertrand Russell, Ludwig Wittgenstein (who contributed to logical truth and linguistic semantics), and even to computer science and software engineering for " $a$ stronger philosophical and foundational basis for this analysis" (Gackowski, 2011, p. 6), as if it mattered. In real-life operations, words are used mainly as code words, with nuances of linguistic semantics being lost; even worse, in politics they are used to veil the true pragmatic meaning. This is a statement of facts and should not be perceived by reviewers (as it was) as an arrogant dismissal of otherwise relevant contributions of great philosophers, but contributions relevant to other issues. It illustrates how reviewers, instead of taking a position on the necessity of the suggested distinctions, divert attention to (here) secondary issues of demonstrating scholarship.

One expects information to be factual to represent facts. Now one faces ambiguities even in dictionaries. They allow a fact to be "information presented as objectively real" (American Heritage Talking Dictionary [AHTD]. 1997) or "information presented as having objective reality" (Merriam-Webster Dictionary). This may yield disastrous results in operations and is ignored by reviewers. In real life, even outright disinformation is presented so it appears to be true. Therefore, the position presented in this paper separates objective reality (facts) entirely from data that represent them. Here again, academic reviewers recommended the "deepest analysis" of what is a "fact" to "provide a stronger philosophical and foundational basis to the argumentation" (Gackowski, 2011, p. 13), again, as if it mattered pragmatically. For a team of Special Forces, it would become an impediment.

In dictionaries, with regard to objects, a fact is "something that has actual existence" (MerriamWebster Dictionary) or "something having real, demonstrable existence" (AHTD). With regard to events, a fact is "a real occurrence" (AHTD) or "a thing done "(Merriam-Webster Dictionary). Within the context of operations, the presented position assumes the simplest interpretations of facts; however, it adds contingencies that do not yet exist or have not yet occurred but are opera- 
tionally possible and therefore should also be accounted for (e.g., explosives that may explode). All of the above can be summarised as follows. Facts are things that exist, events that occurred, or contingencies that may occur. Organizations rarely or never store facts, particularly with computers; they mainly store symbolic representations of facts, where knowledge or knowing are "mediated" not only by humans but also by information and communication technology (Blackler, 1995, p. 1040).

The factual nature of the received primary information should be tested with regard to the purpose and circumstances of use. Testing takes place within a process of quality assurance that may be tedious. The factual nature of something should be established by whatever procedure is deemed to be sufficient. Thus, the tested primary information may gradually become promoted to primary factual data: a human construct not known in nature, in contrast to information that, at least by some, is considered an inherent aspect of viewing anything in the universe. To this end, even instrumental observations and measurements must be replicated by others to ensure reliability. Again, Blackler (1995) reminds us that knowledge or knowing must be situated and contested (pp. 1040-41), hence analyzed within their context to determine whether they are factual.

This, however, denies the approach of Faucher et al. (2008) to reconstitute knowledge management. They are proud that "none of the definitions are linked to facts" (p. 12) because facts are considered to be true while people are fallible. Fortunately, these academicians are more fallible than practitioners. Products and services "made in New Zealand" are of known quality. If one accepted the statements made by Faucher et al., no one could ever rely on anything that is constructed by humans. In operations, a different approach is used. Whatever is provable or replicable is considered to be of statistically significant reliability or simply operationally true until demonstrated otherwise.

Hence, our familiar data are human-developed factual subsets of primary information, nothing less and nothing more. Data are entirely human concepts derived from primary information that is physically interpreted, not information from data. Data emerge when human cognition moves from a possible representation of reality to a factual representation. These data, not Bellinger's (2004) (see below), may constitute the load-bearing foundation of professionally managed knowledge. Reality of interest always changes. To monitor those changes and maintain current data, one must ensure a continuous flow of feedback information about the system and its environment as well as continuous updating of corresponding knowledge bases.

Many academic publications offer descriptions of data entirely divorced from Blackler's (1995) postulates and from all the known techniques of observation and measurement; for example, data:

- are "relatively meaningless to the user," by McLeod and Shell (2001, glossary)

- "may or may not be pertinent or useful for a particular task," by Alter (2002, p. 162)

- " "often has no meaning in and of itself," by Jessup and Valacich (2008, glossary)

- is "a meaningless point in space and time, without reference to either space or time. It is like an event out of context, a letter out of context, a word out of context, and since it is out of context it is without a meaningful relation to anything else" (Bellinger, 2004, p. 1).

Ten out of 30 reviewed authors consider data as meaningless (Gackowski, 2012a). Thus, the above and similar glossary entries silently mislead mostly students, but the reader will later also see scholars or editors of otherwise reputable peer-reviewed journals. Such statements suggest that data do not require much care; they offend practitioners who collect data with a defined purpose and usually also of a defined or at least expected meaning (e.g., encrypted messages). Data collected with no purpose in mind and no identified circumstances should be excluded from professional knowledge management. Professionally collected data must always be well documented with regard to location, time, and other circumstances of collection. It is disturbing that research- 
ers of global warming chose to destroy collected original (raw) research data, leaving only the "processed" ones (no one can now check how) and systematically obstructed access to their data under changing reasons. The Sunday Times reported (Leake, 2009) the following:

1. David Holland, an engineer from Northampton ... requested the figures under [the] freedom of information law; he was refused because it was "not in the public interest."

2. Others ... were turned down because they were not academics, among them McIntyre, a Canadian who runs the Climate Audit website.

3. A genuine academic, Ross McKitrick, professor of economics at the University of Guelph in Canada, also tried.... The [unit - Climate Research Unit (CRU)] told me they had obtained the data under confidentiality agreements and so could not supply them. This was odd because they had already supplied some of them to other academics, but only those who support the idea of climate change." There could, however, be another reason why the unit rejected requests to see its data.

4. This weekend it emerged that the unit has thrown away much of the data. Tucked away on its (CRU) website is this statement: "Data storage availability in the 1980s meant that we were not able to keep the multiple sources for some sites.... We, therefore, do not hold the original raw data but only the value-added (i.e., quality controlled and homogenized) data." If true, it is extraordinary.

Thus, all the rest becomes questionable. It defies Blackler's (1995) postulate that knowledge or knowing are "contestable." This quote, however, experienced the wrath of the "ivory tower." A reviewer (an exceptionally helpful one) rightly wrote that The Sunday Times is not a peerreviewed academic journal or a conference paper, hence provides weak evidence. Truth, however, cannot be attributed exclusively to academic papers, as this paper will demonstrate. This is not an investigative paper. If only one of the quoted examples (among them the last is a self-admitted one) were true, this behavior defies any academic research standards, even if published by peerreviewed journals.

The pragmatic approach to data challenges nearly everything published concerning this subject; however, it seems to be making sense in life. Authors of textbooks richly use the terms "meaning" and "meaningful" but without explaining them. They bestow this adjective upon information, knowledge, and wisdom - never on data. Peirce (1958), a pragmatist and the father of the verifiability theory of meaning, defines meaning as the difference a datum makes when taken or not taken into consideration. Thus, collecting data that may make no difference is an exercise in futility, unless to confirm other data.

Many authors analyzed by Faucher et al. (2008, p. 5) insist on the adjectives "raw" and "unprocessed" with data. A responsible professional knowledge manager would not pollute his system with representations of reality that have not been thoroughly scrutinized. This paper assumes a simple definition of data as "given factual representations of reality." This is not far from the definition proposed by Faucher et al. (2008): "data as basic representation of existence. A purely descriptive construct that requires a low (categorical) level of understanding of existence" (p. 12). The "understanding," however, can be questioned. The term "perception" seems to serve better. For example, individuals may not understand why they are beaten, but certainly they can perceive it and should consider it worthy to retain evidence. What about intercepting encrypted messages? Those who collect them do not understand them. Nevertheless, one expects that, sooner or later, the encryption code may be broken and their pragmatic (not semantic) meaning revealed.

Such a feat had become a decisive factor in winning the Battle of Warsaw (1920), which enabled a young patched-up Polish Army only a few years in formation to stop for 25 years a Soviet plan 
to overrun Central Europe by revolutionary forces to resurrect the Bavarian Soviet Republic in Germany until the Western Allies gave up to them the entire Central Europe in the Potsdam Treaty in 1945. Gill (2011) promotes the use of conceptual schemes or short stories to point out the importance of the presented distinctions otherwise frequently lost to many readers.

ALL authors of the reviewed MIS textbooks (see details in Gackowski, 2012a) omit the etymology of data as something given, already known, or assumed to be true. In discussions of problems in geometry, mathematics, engineering, and so on, the terms givens and data are used interchangeably. This omission deprives data of their natural perspective and context, making it impossible to answer when data are informative. With this aspect unclear, any musings go. Data, the given, cannot be informative to those in the know. If communicated to them, they cannot change what is known. Data, the already given and known, cannot provide any stimulus, as Boland (1987) suggests. The mathematical theory of communication by Shannon and Weaver (1949) makes no known syntactic assumptions, as Fricke (2009, p. 139) claims, but assigns a ZERO amount of information to unnecessary (overlapping) communications. The qualitative theory of information by Mazur (1970) even proves that the formula for the amount of information can be derived without referring to probabilities - another leap in science.

If data are captured on behalf of many users, as practiced in most organizations, then the organizational data are NOT immediately available, given to, or known by users; such data must be communicated to them. Then such data are informative to the end users, not inferred, as Fricke (2009, p. 133) claims. This is about what students are currently taught. It leads to a pervasive impression that data are the main source of information, while, actually, someone else's data may only be a source of secondary information (Gackowski, 2012a, Appendix). The latter, however, also cannot be accepted at face value unless one trusts the source, which is risky with con artists. (A comment to the reader: The last term serves at the request of some reviewers as a substitute for specific financial affairs with names lest no one may become offended by an academic paper.)

Thus, primary data are factual subsets of primary information meant as factors in form that are obtained by whatever means from direct sources. It resembles Fricke's (2009) critique of the DIKW Hierarchy: "All data is information. However there is information that is not data" (p. 140). The difference between data and information is as simple as that of a factual nature that is already available to the user, given, known, or assumed to be true, while the rest of the factors in form remain uncertain with regard to their factual nature. Actionable reliability of information is a function of about 20 contributing factors (Gackowski, 2012b). There is no hierarchical dependency of information on data. The reverse is true.

When summarizing, one always deals first with initial, untested, raw primary information. Only after a thorough scrutiny may one accept it as factual data that must be firmly embedded in space and time, in contrast to Bellinger's (2004) claims. Thus:

1. perception of reality, as presented by experience, provides humans with only an initial glimpse of existence - the original pattern in form that is the untested primary information that is "mediated" by senses, instruments, or technology in general, always "situated,” "provisional," "pragmatic,” and “contested,” as postulated by Blackler (1995).

2. those perceptions must be "contested" by quality assurance including auditing.

3. the factual (proven or at least replicable) become the primary data, a subset of primary information. The rest remains some uncertain primary information that is subject to further examination, the subject of inquiry, opinions, and discussion.

4. monitoring reality for feedback keeps the data current, as they are only "provisional." 
The above are the first four steps of cognizing the pragmatically reconstituted information, data, and knowledge management. Faucher et al. (2008) rightly perceived such a need. How to do it is open for discussion of various approaches, among them the one presented here.

\section{Section 5: Data: A Call for Context, Focus, and Perspectivism}

In the previous section, the four quoted opinions concerning data (tens similar could be used) demonstrate the disparity of views presented with no critical comments: how data viewed by academics who otherwise proved to be bold and critical individuals (questioning the DIKW hierarchy certainly was not welcomed with open arms) turn out to be entirely divorced from practice with data. Here, the example of a loan officer will be used but could easily be substituted by an immigration, customs, or homeland security officer.

Fricke (2009) thoroughly criticized the DIKW hierarchy. First, he followed Ackoff (1989), who views data as symbolic products of observation, which does not raise objections except for his lack of mentioning the indispensable quality assurance. Ackoff (a system and control theorist) did not mean observation "without reference to either space or time," as Bellinger (2004) puts it. In the next paragraph, however, Fricke (2009) tries to improve on Ackoff and "generalize" gathering data "well beyond automatic instruments" (p. 133). He possibly dislikes knowledge that is "mediated" by technology. So, unfortunately, he continues: "When, for example, a person fills in a form giving their name, address, age, social security number-those inscriptions are data. (Actually, the term 'raw data' seems apposite)" (p. 133). This fails the test of reality. Now, the reader will see the same complemented with the indispensable context, focus, and perspectivism (2010).

When, for example (in a business context), a person (an acting entity, applicant, or client) fills in a form (a loan application-purpose), giving his or her name, address, age, and Social Security number to a loan officer (the apex of the perspective), who works for lenders - banks, with the purpose of earning interest and commissions of defined materiality (the grand total of the interest paid over the life of the loan to the bank minus the commission for the loan officer) by closing loan contracts - this is the task or business transaction on which he focuses attention. All of this is viewed through the lens of the decision maker who deals with an unknown and unidentified person-the prospective client. Would a responsible loan officer accept them and say, "Those inscriptions are data"? Data should be factual, but those inscriptions may represent a stolen identity. So, even Fricke ignores Blackler’s (1995) postulate that knowledge must be “contested.”

The example above illustrates how acknowledged reviewers, authors publishing in, and even editors-in-chief of peer-reviewed journals of otherwise well-deserved reputation are prone to undisciplined thinking about data. Knowledge is always "situated" (Blackler, 1995, p. 1042). Thus, for instance, 200K US dollars, more than half a billion dollars for Solyndra, the poster child for green technology, or more than a billion dollars with MF Global run by the honourable Corzine, who does not know where to find them, might be at stake. Hence, the so-called "inscriptions" are merely some uncertain primary information (maybe "raw") given to a loan officer who must put them through a wringer of quality assurance. This aspect is missing in all discussions about knowledge management. Data, so mercilessly denigrated in academic literature, deserve more attention before being accepted as factual.

Here again, I admit with no hesitation, that the best, the most thorough, competent and helpful reviewers I have encountered literally cringe at pointing to specific examples of undisciplined thinking about data. One can see that they understand the need for evidence, but, when provided, they are afraid to offend readers, fellow editors, journals, etc., that can be inferred anyway. Maybe in the short run, they are pragmatically right, but it does not bode well for effective academic discourse. 
The presented position proposes that the model, steps, and terminology of human cognition need to be extended by the notion of primary information and factual primary data that are clearly distinguished from secondary information and secondary factual data with explicitly interspersed corresponding quality assurances throughout the entire cycle. Similar rigor is required for every element of managed knowledge and concepts and the pragmatic aspects of wisdom that are discussed later.

\section{Section 6: Information: A Call for Pragmatic Thinking}

As in Section 5 about data, this section focuses on the disparate views of information. Rowley's (2001) detailed, page-long, anthropocentric exegesis (with about 16 references to books and journal publications) about widespread views of "information as derived from data" (pp. 171-172) reminds his readers of the history of astronomy. In science, consensus proves nothing. In a melee of "nihil Hercules contra plurimus" in science, just the opposite holds true: "nihil plurimus contra Copernicus."

One deals here with academic musings such as "information is data formatted, shaped, organized, processed, interpreted, understood, meaningful, within context, embodied in signs, making decisions easier, endowed with relevance and purpose" (Gackowski, 2012a, Appendix). Some of them (formatted, shaped, organized, interpreted, or within context) may improve presentation of data and efficiency of their use. For instance, dihydrogen monoxide changes its states from solid ice, over liquid water, hot steam, to gas. Each state is a qualitatively different physical state that requires a physical transition. This is in sharp contrast to formatting, shaping, putting in context, or organizing data that do not qualitatively change their nature. Why do these authors suggest a change in name from data to information? Other adjectives such as the following also are used:

- Processed: Information is meaningless without an explanation of how it is processed.

- Understood: Understanding depends on the audience and the presentation, which does not belong to data properties.

- Embodied in signs: Signs do not embody anything on their own until users agree on a specific interpretation.

- Endowed with relevance and purpose, but these are properties of the context of their use, not data properties.

While information and data constitute the building blocks of knowing, alas, all 30 reviewed authors ignore Blackler's (1995) postulates. Now the reader likely is left with an impression of a destructive critique. What actually matters? This question is difficult or impossible to answer without a specific context, focus, purpose, and perspective. It explains the startling ineffectiveness of the authors of the DIKW hierarchy and, later, their otherwise correct critics. Once, however, one starts viewing information, data, knowledge, and wisdom as patterns in form that serve as tangible factors in operations or an extension of provable or replicable knowledge, particularly when viewed through the lens of decision making, the questions can be answered with relative confidence. For instance, a symbolic pattern in form that is serving as a factor in operations ought to be:

- interpretable, hence associated with anything familiar to the direct user

- relevant; hence, it pertains to any factor in the user's mental/ formal model of operations

- meaningful; hence, it makes a difference in the results of operations

- of significant materiality when the difference in results exceeds the threshold of significance for specific users

- on-site available, hence accessible to the direct user where the task is performed

- on-time available, hence accessible to the user before an opportunity expires 
- reliable, hence actionably credible and/or at least actionably believable to act on it

- effectively usable; hence, in addition to all of the above categorically necessary use requirements, if it also meets other situation and task-specific necessary factors

- useful, hence usable, operationally complete (with other task-specific necessary factors), and engaged in operations

Operational completeness as task specific is a different concept than completeness of rows and columns in database tables or completeness of mapping of reality into states of information systems. Only these are currently studied to the detriment of effective operations. Operational usability, completeness, and usefulness of factors including information are of definable pragmatic material consequences, NOT a subject of linguistic semantics. How is it possible that the above universal or categorical use requirements for any factor including information, data, elements of knowledge, concepts, or even the later-discussed pragmatic aspects of wisdom are neither falsified nor recognized?

\section{Section 7: Materiality of Factors (Information and Knowledge)}

Still, it is stunning how the most important use quality of any factor including information-its utility value or, better, net utility value of its use-is ignored or superficially treated.

- Utility value of a factor's use is usually defined as the difference between the results when acting with and without it (Kofler, 1968). There is, however, an important distinction between subjective and objective utility value.

- The subjective utility pertains mainly to decisions made by consumers or end users. It reigns supreme in retail markets and in surveys of end users. It may be reduced to the difference between emotional desirability of acquiring an item and emotional discomfort of parting with some amount of money. The best pragmatic measure is the amount of money consumers or end users are willing to bid for the item. This should not be confused with what they may say (in surveys) that they will do but not necessarily do so.

- The objective utility is assessed from the perspective of a defined purpose. It mainly applies to organizational contexts by comparing the results with regard to the purpose of operations and the cost and effort of procuring the factor. In business auditing, it is called materiality. This objective utility is what cements organizations, and a lack thereof leads to disintegration.

Significant operational materiality of using factors plays the supreme role over all the remaining use requirements. In operations, it is not only a categorically necessary primary requirement but also the fundamental, central, and most pervasive requirement related to the use of all factors including information. In many cases, it can be interpreted as recommended by the Generally Accepted Accounting Principles (GAAP). Thus, significant materiality reigns over all other aspects of information, data, knowledge, concepts, wisdom, and informing (including information processing) except for research of unknown phenomena. Materiality is:

- fundamental — because it is the only necessary use requirement (it is not commonly assumed to be a property of the factor) that provides each factor with a sufficient reason to consider its use in operations.

- central-because it is indispensable for all considerations about effectiveness and efficiency of operations; it ranks or orders all factors. 
- the most pervasive use requirement-because it determines the materiality of the remaining necessary quality requirements of the same factor; it determines the materiality of its necessary companion factors in tasks, and, to a lesser degree, it affects the materiality of indirect factors related to a direct factor.

There is likely nothing more compelling to teach students than the concept of operational materiality of factors. The reality is the opposite. The only exception among MIS textbooks is Alter (2002), who mentioned it mockingly: It is “more elegant than practical” (p. 162). This illustrates once more how "blind" examiners of the metaphorical elephant (information, data, and knowledge) miss the central focal point of all considerations and the most fruitful perspective possible.

Here again, reviewers are torn apart; others cringe. One boldly asks, "Who are the blind scholars and practitioners?" as if 30 authors of MIS textbooks (Gackowski, 2012a) were too few. Another recommends mellowing the statement by adding "can” before "blind," as if it were only a possibility and not a fact. Hence, it needs a strong example. The enormous materiality of knowledge can be illustrated by this comparison: The knowledge of how to build only the first two atomic bombs sufficed to convince Japan to capitulate in August 1945 at the cost of several hundred thousand casualties incurred only by Japan (even less than by conventional bombing of Tokyo and Dresden) versus the projected several million casualties by both the USA and Japan in the case of a conventional landing (source: Lanning, 2005).

Material is not explicitly listed among Blackler's (1995) postulates regarding knowledge but is not foreign to him. Three pages before he started articulating his alternative approach, he stated, "Knowing is situated, distributed, and material" (p. 1035 with added emphasis). Therefore, one may suggest a slight extension of Blackler's postulate that knowledge is pragmatic by "being significantly materially consequential” (emphasis added) with regard to impact. In operations, it mainly means impact on the purpose of using knowledge. This is based on the universal or categorical postulate of teleological perspectivism (Gackowski, 2012b) and (at least) restricted relativity of all assessments, as postulated by Einstein (1961), for operations limited to planet Earth.

There are, however, in Blackler's (1995) work, obsessive references to "types of knowledge that capitalism currently demands." He never defines them but mentions then several times (pp. 1021, 1026, 1031, 1038, and 1040). They are inconsequential to his seminal contributions of how knowledge should be viewed, but these innuendos imply something questionable or sinister, while Blackler ignores the unacceptable political pressure exerted upon scholars in alternative social orders and implies that, somewhere, better ones exist. Economy is a law of nature and societies. Advances of technology, industrialization, and theories and strategies of management more likely determine what kind of knowledge is needed, as demonstrated in Gackowski (2011).

\section{Section 8: Secondary Informing, Secondary Information, and Computer Data}

The previous four sections deal with the initial steps of cognition and laying the foundations for knowledge that rest upon factual primary data. The focus of this section is on spreading the originally developed data to those who use them.

Researchers, practitioners, or users not involved in the process of primary informing must acquire data by a process of secondary informing (communicating, reading, analyzing, etc.) about someone else's derived primary data. This way, data are extended from the original researchers or observers to others. MIS textbooks reduce the entire problem to information derived from data (persistently described as raw and mostly meaningless). In this position paper, such information is 
labelled as secondary information obtained by secondary informing (Gackowski, 2012a, Appendix). Secondary information should also not be taken at its face value, including computer data.

Most quality problems with information are nontechnical; they are inherent to living entities, including humans. Communications are always biased by purpose and frequently deceptive; most living entities try to appear at least a little different. This is a universal principle. Some bias may result from ignorance: a conscious or subconscious deviation from the truth, only truth, and the entire truth. Disinformation and bias are of highest importance and must be dealt with first. Purpose may constitute any commercial, administrative, military, or educational value; it may be even of an entertaining, social, or personal nature.

Receivers and senders of communications aim at some payoff. At the receiving end, communications reaching living entities are biased by ignorance, instinct, and wishful expectations. Humans can barely validate routine facts at an acceptable level for practical activities. At the source (the sending end), communications are biased on purpose, intentionally or subconsciously. From the communicators' perspective, one may distinguish perfectly effective communication, partially effective communication, miscommunication, and discommunication. It affects many; hence, it carries more weight than what occurs to an individual at the receiving end (Gackowski, 2012b).

At the entry side (the receiving end) of those informed (clients, users, etc.), whether active or inactive, problems of presentation quality occur, while utilization problems occur at their exit side. Thus, entities informed might again become a new source of outright disinformation and intentional bias by selectively sharing and/or propagating some information (e.g., Stalin, being admittedly informed by his intelligence that Japan was preparing to attack United States interests, did not warn the USA, but saved Moscow by moving his tank division from the Far East to the Western front).

Computer-processed and stored data values are merely representations of something determined and entered by or on behalf of the end user who originated them, or they are the result of computing. They also cannot be accepted at their face value. Computer data values should be:

- checked for and rectified regarding detected quality deficiencies;

- faithfully (one-to-one or with sufficient accuracy and precision) mapped into states of computer information systems, as defined by Wand and Wang (1996);

- not wilfully or inadvertently distorted during the data-entry process; and

- not corrupted while processed according to the prescribed procedures (e.g., the infamous valuation of mortgage-based securities that were later dumped on the taxpayers) and/or by database design, as defined by Oliviera, Rodrigues, and Henriques (2005).

All of the above require planning, design, implementation, monitoring of procedures, including internal and external auditing, and subsequent enforcement to bridge the inevitable gap that separates the conventionally defined data values from the data values stored by computers. Computerprocessed and stored data are not by default equal to conventional data that symbolically represent facts. To bridge the gap, an adequate quality assurance and flow of feedback information must be in effect.

Secondary information constitutes a separate challenge for researchers and practitioners dealing with information, data, and related technology. Management that ignores quality problems manages chaff and grain on equal terms. Thus:

1. primary data are made available to others within the process of secondary informing that produces the secondary (type of) information.

2. secondary information also should be "contested" by quality assurance whether they can be moved to the category of secondary factual data, a subset of secondary information. 
From the perspective of the end user, what does not pass the test is still some uncertain secondary information.

3. monitoring operations for feedback is necessary to ensure that data remain current because they are only "provisional."

The above are the next three steps of cognition within the pragmatically reconstituted information, data, and knowledge management similarly attempted by Faucher et al. (2008) and continued in this paper.

Before focusing on knowledge, one must remain aware that quality assurance of secondary information produces secondary factual data and then only if respective proofs or replications confirmed them. What remains is only some uncertain secondary information under examination and should be marked as such. Again, secondary information, including computer data, are mediated, situated, provisional, and contested factors in form in contrast to abstract, decontextualized entities. Only quality assurance can ensure that they are factual. For operations, the secondary information also needs to be "significantly material" lest it be ignored as useless.

\section{Section 9: Knowledge and its Components}

Knowledge manifests itself in many ways. It is what one knows, or, more broadly, what society knows. It may be in substance (e.g., objectified in products, services) or in form (e.g., information, data, rules of reasoning and proceeding); it may be formless, tacit (e.g., implied, not explicitly articulated, skills mastered), or even yet undefined (e.g., ideas, intuitions, instincts). Knowledge may be viewed as the totality of patterns in form that symbolically represent actionably reliable data, relationships among data elements, rules of reasoning and proceeding such as the propositional and procedural "know-thats," "know-hows-to-reason," and "know-hows-to-proceed" (skills), in addition to concepts, methods, and topologies, including sequences of state transitions of robots-programs; all of them can be stored in knowledge bases.

Concepts are insights into potential solutions to a question of how to act (e.g., patents). What one does not know, one tries to learn (acquire). New facts, properties, relationships, and rules of procedure, after they have been recognized as valid (provable or replicable), are added to what was known before. Thus grows the body of knowledge of individuals, organizations, and societies.

Manufactured products or rendered services are also manifestations of prior knowledge. By deconstructing and replicating those products and services, one may reconstruct the knowledge in form that enabled someone to build them. Anything provable or replicable with a statistically significant level of confidence is part of scientific and technological knowledge. What is left may still belong to commonly shared meanings and beliefs that are part of the human culture but are not yet science. They still may remain the subject of inquiry. As such, they are subject to knowledge management (research, deliberations, and discussions), but they should be marked as "knowledge-in-progress."

Reality of interest, existence as reality presented in experience, and our knowledge are changing; hence, they are always "provisional.” Anything known must be monitored to remain current. One monitors not only known factors of significant impact, but also, the non-routine factors that MAY impact operations only should be considered separately. They are the realm of research, development, and strategic management that was extensively pursued by Gill (2010). Those recognized as significantly material change situations qualitatively and quantitatively because they represent factors not yet accounted for. If successful, it leads to new solutions. They extend our scientific knowledge. As far as possible, knowledge is presented here in a pragmatic manner, which facilitates its codification and storage in managed knowledge bases (Gackowski, 2012b). 
The above does not deviate much from the articulation of Faucher et al. (2008) about knowledge as a "procedural abstraction of existence" without which "lower levels of abstraction (information, data) are not actionable” (p. 12). Similarly, Fricke (2009) refers readers to Ackoff, who says that "knowledge allows an agent to promote information to a controlling role-to transform information into instruction" (p. 133) - the feedforward or control information in contrast to feedback information. One may summarize that knowledge entails a collection of "know-thats," "know-hows-to-reason," "know-hows-to-do" (skills), and "know-whys" that represent different levels of understanding and mastery of existence. Some of the "know-hows-to-do" is of a tacit nature, such as skills (riding a bike); they can be served indirectly by storing instructional materials about how to acquire such skills. All components are "mediated, situated, provisional, pragmatic, and (continuously) contested,” according to Blackler's (1995) postulates, and one may suggest adding pragmatic of "significantly material" consequences. However, purposeful operations are conducted not haphazardly, but according to some developed concepts and models.

\section{Section 10: Concepts, Models, and Enlightenment}

Without a concept or a pre-developed model, actions are only reactions. Information, data, and elements of knowledge are factors in form for operations that are similar to other factors in substance. They all, however, are combined into a system of operations by some vision, purpose, concept, or only mental or formal model of accomplishing something purposefully.

Concepts are insights into potential solutions to a question of how to act (e.g., patents, inventions). What one does not know, one tries to learn (acquire). Separate fields of strategies, tactics, operations research, management sciences, and decision sciences deal with this problem.

Faucher et al. (2008) add Enlightenment as the upper boundary of the reconstituted knowledge management within their model from Existence to Enlightenment (E2E) that is meant as a "cognitive system of knowledge"; then they explain, "It is not something to have; it is a state of being such as existence" (p. 12). Again, AHTD and Merriam-Webster put the first emphasis on the act of enlightening. A state of being, either for Existence or for Enlightenment, is a risky proposition. As long as we live, we continuously experience reality; we are not frozen in an unchanging state. A static state, which the term implies, could only be a contributing factor, never something driving actions. The quoted authors do not provide a coherent definition of this term, only a reference to an equally undefined "awakening." One may ask, awakening to what? If the object of awakening is not identifiable, observable, or measurable, it cannot be considered part of scientific knowledge. Is it an example of what one can now get away with in a doctoral dissertation?

This is the reason for the initial intention of leaving this section blank. Enlightenment, as described above, as a state or a process of being is peculiar to an individual and not replicable. It may be unwise to pursue the subject in the presented form. Let it be answered by those who see it otherwise and can prove or demonstrate it. At any rate, it cannot be generalized; thus, it seems to be beyond reach of science and scientific experiments. Some may even consider it as being redundant, others as still a valid subject for inquiry and discussion but not likely as part of science.

One may, however, take a pragmatic approach and bring the lofty but murky term down to earth. One may view enlightenment, contrary to Faucher et al. (2008), as a process of an insight when the generation of concepts begins. It is experienced by inventors and discoverers as a fleeting event, not a state. Such an approach may turn out to be more effective in explaining something, or it may be an approach to action. Then, however, the product of enlightenment, or simply insight, despite the fact that it is still a peculiar incident, could be subject to testing, assessment, and comparison with regard to its effectiveness in whatever manner the latter is defined. This view might turn out to be the right one in attaining some pragmatic consequences of defined tangibility and materiality, even replicable and measurable, not directly by itself, but of its product. This physi- 
cal, pragmatic, operational direction of thinking about enlightenment, not the one with a capital E, may be more productive and promising of progress.

\section{Section 11: Operations}

Similar to information, data, elements of knowledge, and also concepts must be tested with regard to their effectiveness, ethics, and efficiency - the triad of praxeology. There is a known saying that the ultimate proof is in the eating of the pudding. No amount of quality assurance, experiments, and testing will ensure the outcome; they must be tested in real-life operations.

Operations are processes that are conducted by at least semi-autonomously acting humans, their organizations, systems that are controlled numerically by programs, and/or by artificial intelligence. They may include natural processes. Planned operations are triggered after an analysis of the situation according to a specific strategy, concept, and/or model. Operations are subject to the competitive, collaborative, and/or adversarial motivated will of participants. Will (drive) is a sufficient reason to act (Schopenhauer, 1847/1974).

However, since the dawn of mankind, the notion of wisdom has been held in higher esteem than anything else. As the reader will find in the next section, not only according to the presented approach, but also by many other authors, it is, or seems to be, unattainable when approached headon or directly. One may, however, assess the pragmatic results of unwise decisions and actions. If so, only by conducting real-life operations may one realize the consequences of unwise decisions and obtain an indirect insight into what wisdom may pragmatically mean.

\section{Section 12: Wisdom: Knowing how to Use Knowledge and Act}

Wisdom is rarely discussed despite the fact that it is the oldest term, while data is the newest term in English (Faucher et al., 2008, p. 4). Faucher et al. (2008) summarize it in their reconstituted knowledge system as follows:

Wisdom is understood as a meaningful, procedural, and justified abstraction of existence based on experience. It has a purpose, relates to procedures, but it is also based on a coherent judgment of existence justified through experience. Wisdom therefore permits sound action and use of experience. Wisdom requires a higher level of understanding than data, information, and knowledge. (p. 12)

Wisdom must be so illusive and controversial that even the editors of the Encyclopedia Britannica did not offer a separate entry for it; it also is a construct that is strongly related to human spirituality and philosophy. According to AHTD, wisdom is an understanding or an insight into what is true, right, or lasting, ranges from common sense through good judgment, the sum of knowledge acquired through the ages, even up to illumination or enlightenment. Thus, wisdom is much more than rationality in decision sciences, where we are confined to bounded rationality (Simon, 1956). Later, Kotarbinski (1961) even discovered a paradox inherent to pursuing all kinds of perfect rationality that, ultimately, makes wisdom unattainable. On this subject, a Chinese philosopher of technology (Tsing, 1993) commented, "His [Kotarbinski's] approach is not inferior to Hume's problem" of causality (p. 249). This problem has not been solved since Hume articulated it; hence, it is one of the highest recognitions in philosophy. In his ethical system, Immanuel Kant articulated the categorical imperative as an unconditional moral law that applies to all rational beings and is independent of any personal motive or desire (AHTD). For humans driven by emotions and desires in all their actions, it is even less attainable than rationality. 
Those interested in a broad interdisciplinary approach to wisdom development may find a goldmine of references in the Information Science Reference book by Targowski (2011). While unable to transcend the bounded rationality to attain higher levels, we may be tempted to abandon all hope for a tangible progress towards wisdom. What might wisdom mean?

1. To be wise, one needs knowledge. Socrates, considered very wise, claimed that he knew nothing - an overstatement, but he developed a method of acquiring some knowledge.

2. Whatever knowledge one possesses, it ought to be used (act in accordance with the knowledge) (Fricke, 2009, p. 141). If not used, it becomes squandered knowledge or talents, which is, by the way, exceptionally mercilessly punished in the Bible.

3. Knowledge should be used ethically; it is necessary but still insufficient.

4. Knowledge should serve a greater common good. And, finally,

5. Knowledge should be used prudently within the confines of the golden rule of moderation by refraining from extremes by considering further consequences (e.g., how to recognize and avoid dangers (Nozick, 1989).) It is known that, sometimes, even wellintentioned actions may cause more harm than good (e.g., helping an elderly person to get up after a fall without checking for possible injuries, according to procedures taught to nurses: "first, do no harm").

When looking through the lens of decision making, wisdom seems to apply to:

- $\quad$ selection of purpose (“appropriate ends" (Floridi, 2008), "within the context of goals and values of life” (Awad \& Ghaziri, 2004, p. 40)

- articulation of ethical requirements with regard to people (recruitment of management and staff), environment, methods, and means of operation

- assessment of results with regard to selecting criteria

Wisdom operates on a higher ground than the still unattainable perfect rationality. Most scholars give up on this subject because it seems impossible to make any head-on progress when one only partially agrees with the characteristic of wisdom listed before. One cannot measure advances in wisdom by the natural pragmatic operational difference in results due to the lack of any reference point. As before, this position paper sets aside all disputes related to wisdom that belong to the realm of linguistic semantics.

This paper focuses on a limited scope of wisdom of knowing how to use what we know within the business context. To the surprise of too many, pragmatism may shed some light of hope. Following Nietzsche's contributions of perspectivism (2010) to the theory of knowledge, this position paper reverses the perspective by 180 degrees. Instead of trying to reach the higher, unattainable, levels of wisdom, one may reduce the scope of attention to the adverse effects of lack of wisdom, of unwise actions and behavior.

One easily assumes that ethical, moral, legal considerations, or the lack thereof, are not quantifiable. A free market of goods and services shows how much of always limited resources are wasted to prevent and fight unethical, immoral, and illegal behavior; it sends measurable signals about the pragmatic consequences of unwise choices. Of course, this requires a free market that is not contorted by politicians. Under a distorted Constitution; neither individuals nor business entities can be certain of how they may be, nor in the future will be treated (and with how many exceptions?), but certainly not equally by a law that is meted out by a blindfolded Roman goddess Justitia; a rapidly vanishing practice.

On one hand, within the sector of information technology alone, an entire industry of products and services mushroomed to address the issue. On the other hand, with relative ease, one can as- 
sess the fast-growing cost of the law enforcement, prison, and parole systems in general. It likely provides only a fractional indication of the costs that the breach of ethics and morality, and the minimum of morality-legality_-burdens society. Contrary to the benefits of wise decisions that no one is capable of assessing, the cost of unwise choices is assessable. Thus, by focusing attention on the most costly unwise choices in a society, one may re-enter the realm of the measurable, hence likely manageable. The essence of what this position paper offers with regard to wisdom is by focusing on developing knowledge of addressing what causes or significantly contributes to unwise choices and behavior that burdens all of us.

Nevertheless, there always lingers another controversy or myth. Are communicated information data, knowledge, concepts, and wisdom intangible and subjective?

\section{Section 13: Tangibility, Objectivity, and Materiality of Data, Information, Knowledge, Concepts, and Wisdom}

Differences in perceiving information, not as a communicating pattern of physical states, but as triggered subsequent associations, thoughts, ideas, and reactions of particular individuals, lead to a common perception that information is subjective, existing only in human minds (Buckland, 1991, p. 3; Callaos and Callaos, 2002; Dervin, 1983, p. 7; Neill, 1992, p. 34). This is the consequence of misplaced focus from what informs to what it may trigger. For example, radio signals (patterns in form) may trigger explosions of improvised explosive devices. These reactions are built into devices or planted into the minds of suicide bombers. Hence, explosions may be triggered by signals, but no one labels them information. Information as a communicated pattern of physical states exists independently of human minds; it may be generated by humans, living organisms, computers, robots, or even by inert matter (nucleus of crystals). Information does not necessarily reflect reality; it may represent contingencies (possibilities, mutations); it may fake it, even disinform on purpose. Once the original pattern is generated by the informing entity, its image exists independently of the originator during its respective life cycle until, over time, it fades away (e.g., radio signals, inscription on a grave stone, seeds).

The physical view of information provides an insight that everything subjective, which is meant as particular to informing and the informed entities, belongs exclusively to them, not to the communication. For instance, with full transparency of communicating computers, or robots, no one attributes any kind of subjectivity to the exchanged messages. The same applies to humans, when particular senders can emit particularly distorted signals, and particular receivers may suffer particular deficiencies in receiving and interpreting them. Quality of factors, including those in form, is subject to quality management and assurance; as with factors in substance, they are equally tangible, objective, and of material pragmatic consequences, which is the focus of this paper.

The least transparent is still the human mind, not the communicated messages. Further advances of technology may gradually enable mapping of the state of the human brain as a system of states of its neuron axons. But researchers may reach natural barriers of cognition that are analogous to that articulated in the Heisenberg indeterminacy principle, which considers how measuring certain properties of a system may unpredictably change other properties of that system.

Information that is viewed physically is as tangible and objective as other physical phenomena. However, the reaction of the entity informed (interpretations, decisions made, and actions triggered) are peculiar or specific. Hence, particular to the entity informed (client, consumer, citizen) and the situation in which it occurs, it is subjective, where here subjective is NOT an antonym of objective; however, human nature tends to project these peculiarities on the communicated patterns that are serving as messengers. Blaming messengers for the messages is as old as humans. The physical view dispels subjectivity of factors in form. A radical departure from subjectivity to physical objectivity, tangibility, and even material pragmatic consequences of information, data, 
elements of knowledge, concepts, and wisdom used as a factor in operations of well-defined context and purpose defies the current deeply held views. It should not be surprising in light of the long-time mankind-attributed movements of the planet Earth to the Sun.

The problem of peculiar reactions is not a subject for informing science. Why one marketer markets products differently from the other or why one consumer reacts differently from the other is a subject of marketing research. Subjectivity originates within the discipline that studies marketer and consumer behavior. The sources of subjectivity always lie within the discipline of the field where information and informing originates or is affected by informing, NEVER with the informing system or the communicated information. Within a well-defined context, factors in form (e.g., information, data, elements of knowledge) play roles as tangible and objective as factors in substance (e.g., material, energy, tools, weapons, etc.), and information processing is as tangible and objective as processing of material and energy. The physical view of information and informing for operations and the extension of replicable knowledge clearly delineates where subjectivity originates and relegates it to disciplines dealing with entities that are generating and using information that intersect with informing.

For those not entirely convinced, data gathered in well-done and described field studies bring in more than only a conceptual scheme that is used to illustrate to the reader the essential but doubtful points. They demonstrate (even unnoticed by their authors) empirical proof of equivalency in objectivity, tangibility, and materiality of information and factors in substance as close as one can get. Alexander Borek and colleagues Parlikad and Woodall (2011), with Polish ingenuity, German rigor (by education), in combination with British empiricism, while working at his doctoral dissertation at the University of Cambridge, UK, did a field study on the subject of risk management stemming from poor quality of information. If one uses the numbers obtained from risk assessment, one can compute the statistically expected risk of injuries and even loss of life due to frequently outdated (15\% on average, p. 9) plans of high-voltage cables (sometimes 100 years old). Of course, the company mitigates this risk by requiring the engineers to use probes before they start working on such cables; however, as with any device, a probe can also fail, causing a risk due to poor quality assurance of testing and calibrating of such probes. Poor quality of factors in substance (e.g., voltage probes) creates exactly the same risk as poor quality of not current cable plans, hence factors in form-information with regard to potential injuries or even fatalities. They are of exactly the same pragmatic material consequences of loss of life or injury by type, size, and value (e.g., insurance premiums against such cases, which certainly the company pays) except for probabilities. This refutes the dearly held notion by many academics of mythical intangibility and subjectivity of information and all other factors in form, as enumerated before.

\section{Section14: The Helix of Human Cognition}

Now, one may summarize everything discussed and stated before as a sequence of state transitions in human cognition that begins with:

1. existence or reality as presented in experience $(\mathbf{E}=\mathbf{R})$, not a state of being, but a process experienced by the being and articulated by

2. $\rightarrow$ primary informing (PIv) into

3. $\rightarrow$ primary information (PIn) as a symbolic pattern of physical states of no other function than their form that are subject to

4. $\rightarrow$ quality assurance (QA1) that yields

5. $\rightarrow$ reliable primary information (RPI) that subsequently is considered as factual data (FD) or givens (G), that is $(\mathbf{R P I}=\mathbf{F D}=\mathbf{G})$ that may be communicated by the process of

6. $\rightarrow$ secondary informing (SIv) into 
7. $\rightarrow$ secondary information (SIn) that requires another

8. $\rightarrow$ quality assurance (QA2) to ensure

9. $\rightarrow$ reliable secondary information (RSIn), subsequently considered secondary factual data (SFD) or secondary givens (SG) that are (RSI=SFD=SG) the building blocks of

10. $\rightarrow$ initial knowledge (IK) that ought to be verified, validated by another

11. $\rightarrow$ quality assurance (QA3) to yield

12. $\rightarrow$ reliable knowledge (RK). Knowledge, for effective use, needs to be combined with

13. $\rightarrow$ initial concepts (IC). They may be products of pragmatically viewed enlightenment (not the one with a capital E) that, again, ought to be assessed by another round of

14. $\rightarrow$ quality assurance (QA4) to arrive at tested

15. $\rightarrow$ reliable concepts or models (RC) (actions or operations without a concept or developed model are only reactions), which, within the realm of bounded rationality, define how one acts upon them and

16. $\rightarrow$ conducts operations $(\mathbf{O})$ that will change the

17. $\rightarrow$ existence or reality as presented by experience from the current or previous $(\mathbf{E 0}=\mathbf{R 0}) \rightarrow(\mathbf{E 1}=\mathbf{R 1})$ to the next one. From this point on, a new cycle of human cognition begins. Then, one starts collecting

18. $\rightarrow$ feedback information (FBI about the outcomes or results that, after another

19. $\rightarrow$ quality assurance (QA5), should yield

20. $\rightarrow$ reliable feedback information (RFBI) that only now enables one to assess the negative impact of UNWISE decisions. We are limited by bounded rationality, hence unable to assess in advance the benefits of WISE decisions and actions. For this purpose, we need a reference point. This can be gained by conducting operations and finding out the seemingly rational, but actually not-so-wise decisions and actions causing unexpected problems. Only now, it is possible to articulate

21. $\rightarrow$ initial control concepts (ICC1) that, after another round of testing and

22. $\rightarrow$ quality assurance (QA6), should yield

23. $\rightarrow$ feedforward control information (FFCI) (Ackoff's [1989] information as instruction) to adjust the operations under one's control and continue to

24. $\rightarrow$ conduct operations (O1) at the next level of cognition, and so on.

The new existence or the new reality (E1=R1), as presented by experience (see Table 1, line 9), is the starting point of a new cycle of human cognition. It can be plotted along an ascending and expanding helix of human cognition if constructive instincts outweigh those that are destructive. Table 1 summarizes how our pragmatic understanding of reality as presented in experience gradually expands and solidifies. 
Table 1: Illustrative diagram of processes and results of developing human cognition that includes interspersed quality assurance, necessary feedback, and feed-forward information (it can be plotted or projected along an ascending and expanding helix)

\begin{tabular}{|c|c|c|}
\hline & PROCESSES & SOURCES - PRODUCTS - RESULTS \\
\hline & primary informing (PIv) & $\begin{array}{ll}\lrcorner \quad \text { existence as reality presented in experience } \\
\quad(\mathrm{E} 0=\mathrm{R} 0) \\
\rightarrow \quad \text { primary information (PIn) }\end{array}$ \\
\hline 2 & quality assurance (QA1) & $\rightarrow \begin{array}{l}\text { reliable primary information (RPI) factual } \\
\text { data (FD) or givens (G) that is (RPI=FD }=\mathrm{G} \text { ) }\end{array}$ \\
\hline & secondary informing (SIv) & $\rightarrow$ secondary information (SIn) \\
\hline & quality assurance (QA2) & $\begin{aligned} & \text { reliable secondary information (RSIn), secon- } \\
\rightarrow & \text { dary factual data (SFD), or secondary givens } \\
& \text { (SG) that is (RSIn=SFD=SG) }\end{aligned}$ \\
\hline 5 & articulation of initial knowledge (AIK) & $\rightarrow$ initial knowledge (IK) \\
\hline 6 & quality assurance (QA3) & $\rightarrow$ reliable knowledge (RK) \\
\hline & $\begin{array}{l}\text { articulation of initial concepts or models of } \\
\text { operations (AIC) }\end{array}$ & $\rightarrow$ initial concepts or models of operations (IC) \\
\hline & quality assurance (QA4) & $\rightarrow$ reliable concepts or models(RC) \\
\hline & conduct operations $(\mathrm{O})$ & $\rightarrow \begin{array}{l}\text { existence or reality changed from the current } \\
\text { existence or reality (E0=R0) to (E1=R1) }\end{array}$ \\
\hline & collection of feedback information (CFBI) & $\rightarrow$ feedback information (FBI) \\
\hline & quality assurance (QA5) & $\rightarrow$ reliable feedback information (RFBI) \\
\hline & $\begin{array}{l}\text { articulation of initial control information } \\
\text { (AICI) }\end{array}$ & $\rightarrow$ initial control information (ICI) \\
\hline & quality assurance (QA6) & $\rightarrow$ feed-forward control information (FFCI) \\
\hline & conduct operations $(\mathrm{O} 1)$ & $\rightarrow$ adjusted existence from (E1=R1) to (E2=R2) \\
\hline \multicolumn{3}{|c|}{ and so on } \\
\hline \multicolumn{3}{|c|}{$\begin{array}{l}\text { Comment: Within the context of this pragmatic approach to knowledge management, feedback infor- } \\
\text { mation entails also consequences of unwise aspects of operations, and feed-forward control information } \\
\text { addresses adjustments necessary to counteract unwise behaviors and actions that cause unintended and } \\
\text { unforeseen adverse effects. }\end{array}$} \\
\hline
\end{tabular}

Now, someone may ask where wisdom can be applied. Wisdom, when viewed as a higher level of understanding than the unattainable perfect rationality, unless someone proves it otherwise, within the context of the presented approach, cannot be applied directly as others believe (Targowski, 2011). Post factum, however, after conducting operations, one is able to pragmatically assess where, to what degree, and at what cost unwise decisions and actions result in waste or simply deteriorate the results. Without first erring, we are unable to assess the benefits of wise decisions because we lack an identifiable reference point so emphasized by Einstein (1961) as needed for reliable assessment and measurements. Only then, according to the materiality of different kinds of unwise decisions and actions, one may, in a quasi-rational way, address them, at the earliest, during the second or later cycles of cognition (see Table 1, lines 10-14 and further).

Hence, when one follows the physical and pragmatic trains of thought, the reality is more complex than the previously discussed hierarchies, models, or sequences of cognition that are published in scholarly literature. The obvious need for quality assurance at different stages of knowledge management and the need for feedback to maintain the current administered knowledge base have been commonly ignored; it was a nonissue, at least, in most academic discussions. 


\section{Section 15: Conclusions}

The position stated in this paper is presented for reflection on the disparities in thinking about information and informing, data, knowledge, concepts, enlightenment, wisdom, the helix of human cognition, and the chasm that frequently separates the views within academia and between academia and practice. The purpose is to trigger a discussion and elicit objections and critique.

Fricke (2009), in his critique of the DIKW Hierarchy, described it as "unsound and methodologically undesirable.” The same applies to the sequence of cognition with regard to information and data. Factual data cannot be obtained without first informing oneself about the surrounding reality or the existence presented in experience. Primary informing provides us with the initial primary information, but the latter must be put through the wringer of independent quality assurance; otherwise, one may end up with unverified perceptions. The presented position fits Fricke's statement that "all data is information. However, there is information that is not data" (p. 140). Data are a subset of information, which is a narrower human-devised construct that needs a more rigorous definition than that offered in MIS textbooks. The same applies to Blackler's (1995) statement that "so-called weak knowledge may prove suitable as an account of information" (p. 140). Information, when interpreted as anything in form, certainly represents a weaker knowledge than data. Its factual nature must be asserted by a rigorous process to ensure quality so that thusobtained data may become actionably reliable for operations. It equally applies to secondary information, if used as a factor in operations. "Formatting, shaping, organizing, processing" (how?), etc., without situation-specific quality assurance cannot accomplish this.

When it comes to Faucher et al. (2008), extension of the scope of knowledge management by Existence at the lower end and Enlightenment at the upper end, where both are interpreted as states of being, and quite contrary to their view, one might achieve a more tangible and pragmatic progress by viewing them as processes of experiencing reality and gaining insights about reality.

A more adequate presentation of the process of human cognition is presented as a process of increasing our understanding of reality, where the process is plotted along an ascending and expanding helix, not as a hierarchy or a closed loop, where the consecutive steps are interspersed with adequate quality assurance, while the entire knowledge base is continuously monitored for feedback from reality to keep it current.

Populating a knowledge-management system by "a notoriously polymorphic phenomenon and polysemantic concept of information,” as described by Floridi (2008, p. 303-329), would be foolish. From an engineering perspective, a professional information-management system should be supported by a solid load-bearing structure of actionably reliable data, provable and/or replicable relationships, procedures of reasoning and proceeding, and, finally, by tested concepts. Later, knowledge-management systems may be augmented by less reliable, more uncertain elements that are retained for further examination, research, studies, and discussions but marked as knowledge in progress.

The physical and pragmatic approach seems to elucidate and demystify many misconceptions surrounding information, data, and knowledge. If information and data serve as factors in operations, their operational materiality can be determined. The key to comprehending and appreciating the physical views is to focus one's attention, not on what information is or might be per se, but, rather, on its role as an objective factor in form in real operations, where the rubber meets the road, where theory meets the corresponding practice. One may only speculate whether, for the same reason, Blackler (1995) preferred the term "knowing” (as a process) over "knowledge." This paper seems to lay the groundwork for more rigorous research and more enlightened practice, as Faucher et al. (2008) prefer. Some frustrated reviewers suggested that different types of knowledge may require reconsidering definitions of data and information within more limited 
contexts. The physical view of information leaves no room for such considerations. Table 2 tries to summarize the disparities of views.

Table 2: Summary of the chasm that separates the academic and the pragmatic views ACADEMIC VIEWS PRAGMATIC VIEWS

\section{SEMANTICS}

Linguistic

Natural (of pragmatic material consequences)

\section{FACTS}

Still require "deepest analysis," studying B. Russell, L. Wittgenstein, and many other sources for " $a$ stronger philosophical and foundational basis for this analysis"

Things that exist, events that occurred, and contingencies that must be accounted for

\section{DATA}

"Relatively meaningless to the user, that may or may not be pertinent or useful to a particular task, often of no meaning in and of itself" or even "meaningless point in space and time ... out of a context ... without a meaningful relation to anything else"

Factual, given, or assumed-to-be-true representations of existence meant as reality presented in experience; firmly placed in time, space, and context for verification and replication; actionably reliable; usable; and useful from a defined perspective

\section{INFORMATION}

"Data (comment: the above meaningless) formatted, shaped, organized, processed, interpreted, understood, meaningful (comment: derived from frequently meaningless data), or "endowed (by whom) with relevance and purpose," aptly summarized by Floridi as a "notoriously polymorphic and polysemantic concept"

If used as a factor in operations, it is as objective as anything in substance (e.g., identifier, time, and location for a drone attack) and seen by some as an omnipresent aspect of viewing matter and energy with regard to structure, organization, or lack thereof

\section{COGNITION}

As a process of deriving meaningful and useful information from generally meaningless data as frequently defined as above

A step-wise process of obtaining primary (initial, raw) information by primary informing from primary sources about existence-reality as presented by experience to primary factual data that are established by quality assurance through secondary information that is obtained by secondary informing from secondary sources of ensured quality through provable or replicable knowledge, up to wisdom, always provisional, and confirmed by feedback as current

Blackler's (1995) alternative approach to knowledge, with the enumerated postulates, may be contested as any other knowledge, but it seems to be holding intact, as it has not been refuted; it equally applies to information and data - the elementary building blocks of knowledge. Useful knowledge should also be "significantly material" (as defined in Section 6), and it does not contradict his line of thinking; it only makes explicit what pragmatic means (p. 1035) in operations.

Nearly all contemporary authors ignore, at their own peril, Blackler's postulates about knowledge or knowing that any information or data, when defined, described, or only referred to, is:

- mediated in whatever manner it may occur

- situated, thus never deprived of context

- provisional, as representing the ever-changing reality or existence that easily may lose currency when monitoring feedback is neglected 
- pragmatic, as being consequential when used in action or operations or for extension of provable or replicable knowledge

- contested by thorough scrutiny or quality assurance, with the suggested addition

- significantly material to be useful in operations with the exclusion of research

If authors kept in their minds the above postulates, many, if not most, disagreements (in viewing information and data as discussed in this paper) would disappear. The first draft of this paper was written without reference to Blackler's (1995) work. It was triggered exclusively by the disparity of the academic and pragmatic views about information and data. Therefore, it is befitting to add that the author is indebted to Adrian Dale for referring him to Blackler's work.

With not many exceptions (e.g., Stonier, 1997) a common anthropocentric bias in viewing information blinds scholars and practitioners by unnecessarily limiting their research and deprives them of instructive examples that only nature can reliably provide. Information, as an objective aspect of viewing matter and energy, need NOT be observed, recognized, and subject to mental processes, but, at the same time, it is the MAIN object of all mental and computerized processes of informing entities and entities informed, which, in turn in operations, use matter and energy to arrange reality by their designs. This paper posits that the physical view of information as patterns of physical states with regard to their form serve as factors in decision making for operations and provides a sound platform and framework for verifiable reasoning and testing of hypotheses about informing.

Nevertheless, the main ideas in this position paper presented over several years are facing an unusual spectrum of reviewers' views, ranging from "excellent relevance," "excellent originality," "interesting," through "of no broader interest or practicality" to "nomologically uninteresting proposition ... neither controversial nor falsifiable." It is likely that no broader spectrum exists; however, with an exceptionally strange regularity, not a single reviewer tried to dismiss or challenge its veracity, by providing any real example to the contrary. No theory can be proven; it can only be falsified. It demonstrates the controversial nature of the problem and a common pattern of human cognition:

1. Initially, anything discovered is controversial until recognized.

2. It may remain controversial for a long time in research and practice.

3. Once recognized, it becomes neither controversial nor falsifiable, until challenged again.

In many ways, likely unintentionally, most reviewers divert researchers' attention from the primary concerns, here knowledge management, to less productive discussions of disrespectful treatment of great philosophers, even when their contributions to linguistic semantics do not apply to natural semantics or how to avoid offending some honorable con artists. Therefore, this physical and pragmatic approach is presented to elicit critique, challenge, discussion, and suggestions for improving primarily its ESSENCE and only secondarily its SCHOLARLY prowess.

Do we indeed need to study B. Russell and L. Wittgenstein to suggest the necessity of the simplest pragmatic distinctions of primary informing from secondary informing, primary information from secondary information, and so on for data, knowledge, concepts and even the pragmatic aspects of wisdom that are interspersed with the indispensable but commonly ignored quality assurance? It is not obvious that a professionally managed knowledge base needs continuous feedback information from reality to maintain its currency. Is it not time to dispel the enduring myth of intangibility and subjectivity of information that is passed as a communicated message with pragmatic material consequences as long they serve as factors in defined purposeful operations? Then, materiality of factors in form is determined exactly in the same way as for factors in substance.

No one denies that linguistic semantics is of high importance for social communication and even development of knowledge. In real life, however, physicians attending sick patients pay primary 
attention to the natural material consequences of their actions. Only when these are clear, may they generalize their cases to communicate their experience and conclusions; this time paying a lot of attention to linguistic semantics of their communications or publications, but, still, this always remains secondary to the natural semantics, not the other way around. The same applies to research and planning of operations that seems to elude many of us.

\section{References}

Ackoff, R. I. (1989). From data to wisdom. Journal of Applied Systems Analysis, 16, 3-9.

American heritage talking dictionary [AHTD]. (1997). The Learning Co.

Alter, S. (2002). Information systems -Foundation of e-business. Upper Saddle River, NJ: Prentice Hall.

Awad, M. A., \& Ghaziri, H. M. (2004). Knowledge management. Upper Saddle River, NJ: Pearson Education.

Bellinger, G. (2004). Knowledge management-Emerging perspectives. Systems Thinking. Retrieved from http://www.systems-thinking.org/kmgmt/kmgmt.htm

Blackler, F. (1995). Knowledge, knowledge work and organizations. An overview and interpretation. Organizational Studies, 16, 1021-1046.

Boland, R. J. (1987). The in-formation of information systems. In R. L. Boland \& R. A. Hirschheim (Eds.), Critical issues in information systems research (pp. 364-404). New York: John Wiley \& Sons.

Borek, A., Parlikad, A. K., \& Woodall, P. (2011). Towards a process for total information risk management. In A. Koronios, J. Jing Gao, B. Laboisse, \& J. Talburt (Eds.), Proceedings of the $16^{\text {th }}$ International Conference of Information Quality, (ICIQ), November 2011, Adelaide, South Australia

Buckland, M. (1991). Information and information systems. New York: Praeger Publishers.

Callaos, N., \& Callaos, B. (2002). Toward a systemic notion of information: Practical consequences. Informing Science: the International Journal of an Emerging Transdiscipline, 5(1), 1-11. Retrieved from http://www.inform.nu/Articles/Vol5/v5n1p001-011.pdf

Dervin, B. (1983). An overview of sense-making research: Concepts, methods and results to date. Presented at the International Communication Association Annual Meeting, Dallas, Texas. Seattle: School of Communications, Univ. of Washington.

Einstein, A. (1961). Relativity—The special and the general theory. New York: Crown Publishers.

Faucher, J. B., Everette, A. M., \& Lawson, R. (2008). Reconstituting knowledge management. Journal of Knowledge Management, 12(3), 3-16.

Floridi, L. (2008). The method of levels of abstraction. Minds and Machines, 18(3), 303-329.

Fricke, M. (2009). The knowledge pyramid: A critique of the DIKW hierarchy. Journal of Information Science, 35, 131-142.

Gackowski, Z. J. (2011). Strategic alignment of information quality: Academic and practical views. Proceedings of the $16^{\text {th }}$ International Conference of Information Quality, Adelaide, South Australia.

Gackowski, Z. J. (2012a). Focus and perspectivism in viewing information, data, and informing: Fundamental distinctions. Informing Science: International Journal of an Emerging Transdiscipline, 14, 1 35.

Gackowski, Z. J. (2012b). Informing for operations: Framework, model, and the first principles. Santa Rosa, CA: Informing Science Press.

Gill, T. G. (2010). Informing business: Research and education on a rugged landscape. Santa Rosa, CA: Informing Science Press. 
Gill, T. G. (2011). When what is useful is not necessarily true: The underappreciated conceptual schema. Informing Science: The International Journal of an Emerging Transdiscipline, 14, 1-32. Retrieved from http://www.inform.nu/Articles/Vol14/ISJv14p001-032Gill589.pdf

Hamlyn, D. W. (1980). Schopenhauer: The arguments of philosophers. London, UK: Routeledge \& Kegan Paul.

Jessup, L., \& Valacich, J. (2008). Information systems today. Managing in the digital world. Upper Saddle River, NJ: Pearson/Prentice Hall.

Kofler, E. (1968). O wartosci informacji (On value of information). Warsaw, Poland: Panstwowe Wydawnictwa Naukowe (PWN).

Kotarbinski, T. (1961). The property of a good plan. Methods, 13(51-52), 189-201.

Lanning, M. L. (2005). The ten battles of all time. Battle \#7 Atomic bombing of Japan, World War II, 1945. Retrieved from http://www.historyplace.com/worldhistory/topten/index.html

Leake, J. (2009, November 29). The great climate change science scandal: Leaked emails have revealed the unwillingness of climate change scientists to engage in a proper debate with the skeptics who doubt global warming. The Sunday Times. Retrieved from http://www.timesonline.co.uk/tol/news/environment/article6936289.ece

Mazur, M. (1970). Jakosciowa teoria informacji (Qualitative theory of information). Warsaw, Poland: Panstwowe Wydawnictwa Techniczne (PWT).

McLeod, R., \& Schell, G. (2001). Management information systems (8th ed.). Upper Saddle River, NJ: Prentice Hall.

Neill, S. D. (1992). Dilemmas in the study of information: Exploring the boundaries of information science. New York: Greenwood Press.

Nozick, R. (1989). The examined life: Philosophical mediations. New York: Simon \& SchusterTouchstone.

Oliviera, P., Rodrigues, F., \& Henriques, P. (2005). A formal definition of data quality problems. In F. Naumann, M. Gertz, \& S. Madnick (Eds.), Proceedings of the 10th anniversary international conference on information quality-ICIQ-05 (pp. 13-26). Cambridge, MA: Massachusetts Institute of Technology (MIT).

Peirce, C. S. (1958). Collected papers of Charles Sanders Peirce. Cambridge, MA: Massachusetts Institute of Technology (MIT).

Perspectivism. (2010). Encyclopcedia Britannica. Retrieved December 3, 2010, from Encyclopædia Britannica Online: http://www.britannica.com.ezproxy.lib.csustan.edu:2048/EBchecked/topic/453084/perspectivism

Rowley, J. (2007). The wisdom hierarchy: Representations of the DIKW hierarchy. Journal of Information Science, 33, 163. Retrieved from http://jis.sagepub.com/content/33/2/163

Shannon, C. E., \& Weaver, W. (1949). The mathematical theory of communication. Urbana, IL: Univ. of Illinois Press.

Simon, H. A. (1956). Rational choice and the structure of the environment. Psychological Review, 63(2), 129-138.

Schopenhauer, A. (1974). On the fourfold root of the principle of sufficient reason. Open Court Publishing Co. (Original revised work published 1847).

Stonier, T. (1997). Information and meaning: An evolutionary perspective. London: Springer.

Targowski, A. (2011). Cognitive informatics and wisdom development: Interdisciplinary approaches. Hershey, PA: IGI Global. 
Tsing, Z. (1993). Philosophy of technology: Epistemological or praxiological? Some lessons from Chinese philosophy of technology. In T. Airaksinen \& W. Gasparski (Eds.), Praxiology: The International Annual of Practical Philosophy and Methodology, Vol. 2 (pp. 243-255). New Brunswick, NJ: Transaction Publishers.

Wand, Y., \& Wang, R. Y. (1996). Anchoring data quality dimensions in ontological foundations. Communications of the ACM, 39(11), 86-95.

\section{Biography}

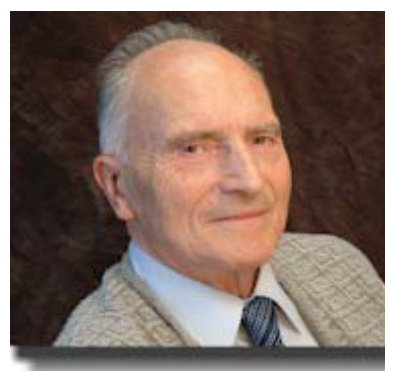

Zbigniew J Gackowski has experience in industry, public administration, and academia. His teaching and research bridge the Central European and US experience in Computer Information Systems (Warsaw Polytechnic, The University of Michigan [Fulbright Research Scholarship], Purdue University [Visiting Associate Professor], Baruch College [Visiting Professor], CSU, Stanislaus [Visiting and Tenured Professor], and the University of Melbourne [Visiting Professor]). His research has received much recognition. While in Poland, he published more than 120 items, among them 4 books and 6 papers in refereed journals and 12 papers presented across Europe, the United States, the Middle East, and South America. While in the USA, he taught at three USA universities and wrote 32 research papers that were published in the proceedings of ASIS, ACM, WDSI, Information Systems Educators Conference, The Informing Science Institute, and the International Conference on Information Quality at MIT (12 fast-tracked to peer-reviewed journals), 4 book chapters, and 1 scholarly book. He is a member of ACM, a charter member of the Association for Information Systems, and a founding member and honorary fellow of the Institute of Informing Science. 